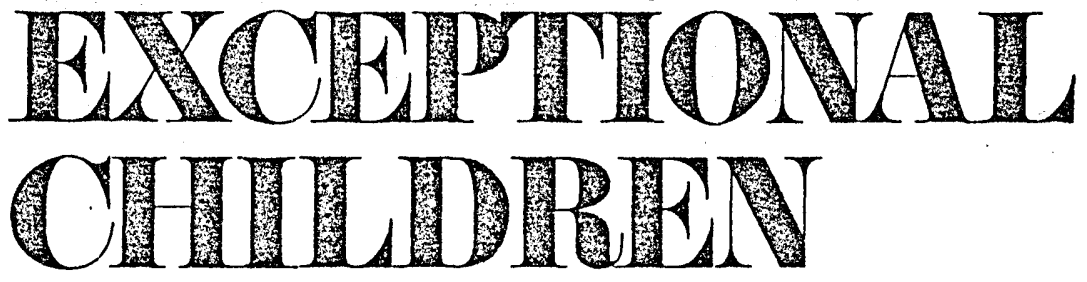

\title{
TEACHER APPLICATION OF BEHAVIOR PRINCIPLES IN HOME AND CLASSROOM ENVIRONMENTS
}

\section{SYSTEMATIC BEHAVIOR MODIFICATION}

\section{Roger L. Kroth, Richard J. Whelan, and Jean Marie Stables ${ }^{1}$}

A cursory investigation of education-related professional literature that has appeared in the last five years indicates increasing emphasis upon the application of behavior principles in home and classroom environments. Behavior principles (Skinner, 1953) are used to analyze, in a functional manner, the frequency of behavior that is directly observable and measurable, and those environmental events that occur immediately before and after behavior. Environmental events affect and determine the occurences of behavior at a specific time, place, and set of conditions (Whelan and Gallagher, 1969), and usually function to increase or decrease specific behavior frequency. Behavior principles, therefore, refer to the connective relationship between behavior and environmental events (Skinner, 1963).

Educationally relevant applications of behavior principles in classrooms for children with academic performance, and nonacademic madadaptive behavior patterns, have been described in other sources. Studies and reports pertaining to Engineered Classrooms (Hewett, 1968) and the Structured Approach (Gallagher, 1968; Haring and Phillips, 1962; Whelan, 1966) represent examples of procedures used in applying behavior principles in classrooms and other child-related environments. A comprehensive description of these procedures is provided in the sources cited and should be reviewed, since the information provided in this article is, by necessity, somewhat limited in scope. The intent and focus of this article are to present some of the recent extensions and elaborations of the Structured Approach through the more systematic application of behavior principles associaled with that concept. Some of the basic rationale relevant to the Structured Approach are stipulated to provide a general perspective. The importance of providing systematic procedures for application of behavior principles to help children increase appropriate behavior and decrease self-debilitating behavior, plus the necessity of evaluating procedure effectiveness, is described and stressed.

The Structured Approach and recent developments in the application of behavior principles have received considerable attention during the past decade. It is not difficult to ascertain the reason for such continuing attention and interest. It is due

1. Dr. Roger L. Kroth is Assistant Professor of Education, University of Kansas. Dr. Richard J. Whelan is Chairman, Department of Special Education, University of Kansas, and Director of Education, Children's Rehabilitation Unit, University of Kansas Medical Center. Mrs. Jean Maric Stables is a Demonstration Teacher, Children's Rehabilitation Unit, University of Kansas Medical Center.

(C) Love Publishing Company 1970 
to a more discerning examination of other behavior change intervention approaches that appear to be only minimally effective in fostering development of adaptive behavior (Eysenck, 1961a; Volsky, Magoon, Norman, and Hoyt, 1965), and the accumulation of evidence (Krasner and Ullmann, 1965; Ullman and Krasner, 1965) supporting successful, positive behavior change through the effective application of behavior principles. As a result, professional personnel associated with social work (Thomas, 1967), guidance (Krumboltz, 1966), child development (Bijou and Baer, 1967), psychotherapy (Wolfe and Lazarus, 1966), and special education (Kroth, 1968), have implemented behavior principles as the primary basis for interactions with children and adults who need support and assistance.

Behavior principles, and intervention procedures based upon such principles, have been demonstrated to be effective in applications with parents (Wahler, Winkel, Peterson, Morrison, 1965), hospital aides (Ayllon and Michael, 1959), and teachers (Whelan and Haring, 1966). More detailed discussion of the rationale associated with the formulation of behavior principles is presented in other sources (Bijou and Baer, 1961; Holland and Skinner, 1961; Michael and Meyerson, 1962). With cognizance of previous research and application, the purposes of this article are to present some basic assumptions and expectations inherent in applying behavior principles, and some examples of application methodology that are relevant for decisions to implement and evaluate effective application of behavior principles in home and classroom environments.

\section{ASSUMPTIONS AND EXPECTATIONS}

Inherent in the application of behavior principles is the assumption and expectation that behavior will not

FOCUS ON EXCEPTIONAL CHILDREN is published monthly except June, July, and August as a service to those concerned with mentally retarcled and emotionally disturbed children. Subscriptions rates, $\$ 9.50$ per year. Copyright 1970 Love Publishing Company. All rights reserved. Reproduction in whole or part without written permission is prohibited. Printed in the United States of America. Second class postage is paid at Denver, Colorado.

\section{Executive and Editorial Offices 6635 East Villanova Place Denver, Colorado 80222 Telephone (303) 757-2579}

\section{EDITOR}

Dr. Edward L. Meyen The University of Iowa
Washington Report

Valeita J. Naegle
Stanley F. Love Publisher only change oxer time, but that planned, organized manipulation environmental events can be used to foster appropriate behavior change. In essence, these assumptions and expectations are the crucial aspects of role definitions assigned to classroom teachers. If it is assumed that behavior can be changed, then a classroom teacher can help children change their behavior by systematic variation of environmental events. Boyer and Walsh (1968) provide information of importance regarding asumptions and expectations pertaining to behavior change principles. It is as follows:

The environmeatal hypothesis may be wrong, but if it is, it should be shown to be wrong only after a society has done everything posstole to develop the abilities of people .... We should base our policy on the most generous and promising assumptions about human nature .... [p. 78]

Adopting a position that behavior can be changed by variation of environmental events, the teacher and child must interest, expect, and expend effort to increase the probability of adaptive behavior change. Acceptance of a diagnostic or classification label as a reason for failure to promote Behavior change may lead potentially to a self-fulfilling prophecy, since failure to expect change can predetermine the absence of change (Rosenthal and Jacobson, 1968). For example, a teacher who is aware of the importance assigned to systematic application of behavior principles would approach deficit performance in arithmetic facts as a behavior capable of being changed, and not nexessarily as a symptom of an unobservable process which precludes all possibilities of promoting change or growth in arithmetic proficiency. As can be noted, this self-analytical approach to child-teacher interaction, in terms of viewing environmental events as potentials to assist children, is a "most generous and promising assumption about human nature." (Boyer and Walsh, op_ cit.)

Assumptions and expectations that are not made are that teachers will apply behavior principles inappropriately because of an inner disposition to dominate or punish children. While behavior principles and application procedures using such principles are neutral, i.c. neither inherently "good" or "bad," there are concerns about providing teachers with instruction in the implementation of behavior principles (Lucero, Vail, and Scherber, 1968; Wood, 1968). These concerns may actually reflect ambivalence regarding the ethical aspects of providing teachers with powerful behavior change procedures. Why such concerns are not expressed for purported effective behavior change procedures such as argery, drugs, electroshock therapy, etc., is not clear except that behavior improvement following 
such interventions has not been remarkable (Eysenck, $1961 \mathrm{~b})$.

What appears to be a realistic basis for these concerns is that some children are exposed to inadequately prepared teachers who may apply effective behavior change procedures in an inept or harmful manner. Therefore, the concerns or criticism should not necessarily be directed at neutral behavior principles. As previously indicated, an analysis of teacher selection and teacher preparation by those professionals responsible for such endeavors is essentially the aspect that should be stressed. Rather than viewing teachers as insensitive individuals who are looking for new procedures to help them control and punish students, it is more realistic to assert that most teachers are seeking specific behavior change procedures which will enable children to achieve and experience success, often for the first time, in school and home situations. It is recognized that a crucial need to improve teacher selection exists, but to deprive teachers of effective behavior change principles and procedures to apply them is grossly unfair.

Basically, the teacher who recognizes the importance of correct, systematic, sensitive, and empathetic application of behavior principles and the necessity to protect individual human dignity is a teacher who believes that behavior is learned, can be changed, and consequently plans changes in self and child behaviors. When behavior change does not occur, an analysis of the childteacher-environment interaction process is required. Teacher expectations of the child for specific behavior performance may be inappropriate, or environmental events have not been arranged in a manner that will enable the child to function successfully.

Inherent in the effective application of behavior principles is the formulation that teachers and children must assume responsibility for their behavior. Within this framework it may be asserted that the "child knows best." That is, teacher knowledge and skill in arranging the learning environment to foster desirable child behavior changes are evaluated for effectiveness by measuring the extent or absence of child behavior changes. A child's responses to environmental expectations are subsequently used to assume efficacy of such expectations in terms of approaching specific child behavior objectives. If the child hits the teacher, kicks a peer, tears up books, etc., the teacher must first complete an analysis of the situation in which the child was expected to function adequately. This includes analysis of task materials, expectations for task completion, and identification of other environmental events which preclude adequate performance, and subsequently elicit unacceptable behavior reactions. It is then the teacher's responsibility to change the environmental situation with the expectation that the child may experience future successes from interaction with peers, the teacher, and materials related to general task completion.

An effective teacher also provides opportunities for . children to participate in program planning for the school day. This may take the form of written and verbal contracts which the child and teacher plan and initiate by mutual agreement. In essence, the child and teacher know in advance what behaviors are expected, and are aware of those environmental events (consequences) which follow adequate or inadequate performance as stated in the contract objectives. Both child and teacher expectations for performance and responsibility are clearly defined. The problem requiring solution is not fundamentally one of the teacher controlling the child, or of the child dominating the teacher, but one of how successful or effective are the child and teacher in planning a realistic, sequential learning process that will produce constructive changes in child-teacher interaction behavior performances. If the child and teacher do not function collectively to develop effective strategies for application of behavior principles to enhance individual coping competencies, then random, unsystematic application of behavior change procedures may operate to promote deleterious effects. Environmental events, and their manipulation by individuals, do influence behavior, and will operate even though teachers and children are not aware of them. Since this situation exists, it is of paramount importance that educators assume responsibility for the correct, systematic, and effective application of behavior principles.

\section{APPLICATION METHODOLOGY}

There is probably substantial agreement that "learning under the control of reward is usually preferable to learning under the control of punishment." (Hilgard, 1965, p. 486) For many children classified as exceptional, programs have been directed at those maladaptive behaviors which society does not accept, but paradoxically does readily recognize. Individuals responsible for implementation of behavior intervention strategies may attend to or stress behavior that is characterized by deviancy, and maladaptive patterns of reacting to environmental variables. Attending to behaviors (verbal, motor ,etc.) with a content of hate, conflict, sexual perversion, and negative aggression may actually increase the frequency of these behaviors. That is, dwelling upon the deviant behavior patterns does not ensure that these behaviors will decrease, and does not auto- 
matically foster the acquisition of acceptable, positive behavior patterns.

Teachers skilled in the application of behavior principles attempt to stress child behaviors that can be followed by pleasurable, positive environmental events (consequences). This type of concern requires a precise analysis of academic and other behavior expectations. Performance tasks, which can be arranged or sequenced into small increments to foster successful accomplishments, enable child-task interaction to be a positive, self-enhancing experience. Instead of expecting a child to read an entire page, the teacher might begin by requesting oral reading of one sentence, then two, a paragraph, and eventually the entire page or story. Through this procedure of approximation to a specified objective-an entire page of accurate oral reading-the child is able to function more independently in the learning environment. While the process appears to be descriptively simple, its correct application requires a great deal of planning and understanding of child behaviors by the teacher who attempts systematic application of behavior principles.

It is known that child-teacher and child-parent relationships can operate to maintain acceptable as well as unacceptable behavior. Merrill (1946) observed mothers interacting. with children in a play situation, and noted that the mothers reacted differently in situations when children were criticized as compared to when they were not. Mothers, when informed that their children were not performing adequately, were observed to increase the frequency of negative, critical comments which were directed toward the child in an attempt' to alter behavior patterns. Mothers who were told that their children were behaving adequately did not engage in a high frequency of critical child-parent interactions.

There is an interest and a necessity to involve parents when programs are planned for exceptional children. Statements such as "when parents and teachers are working at cross purposes, the child suffers" (Voelker 1967, p. 692) are not unusual. Parents have been viewed as a powerful force that can aid in the enactment of favorable education-related legislation, and can influence local boards of education. While some educators may encourage parental involvement because they fear parent criticism, a more altruistic reason may be that it is recognized that parent-child relationships in the home will affect child behavior in the classroom.

It has been suggested that working with parents, either in groups or in individual conferences, can have a positive effect on children's behavior. In an effort to as- certain whether conferences with parents were having any effect, Jessell and Rothney (1965) asked parents and students to indicate what was discussed in the conferences, and whether they considered action had taken place. The students were ninety-five superior' high school seniors. There was a high correspondence between topics the parents said were discussed in conferences and the areas in which students said action took place.

McCowan (1968) studied the effects on counseling with parents, students, or both parents and students on certain academic variables. Underachieving tenth grade students were randomly assigned to treatment conditions, with one group maintained as a control group. Students of all three counseled groups did significantly better on the California Study Methods Survey and on the Home Adjustment Scale of the Bell Adjustment Inventory than the control group. The students whose parents were involved in counseling did significantly better on midterm and final grade averages than the control group, while the students who were counseled without parent involvement did not do significantly better than the control group. The counseling used in the groups was a non-directive, group-centered ap. proach.

A number of single subject studies report that mothers can be trained to apply behavior change principles in developing effective procedures for altering child behavior. Through behavior observation, and behavior recording, the mothers learned to examine and change interaction patterns with children. Russo (1964) had mothers observe a trained therapist who was using behavior principles to change the behavior of children. As soon as the mothers understood, and learned the procedures, they assumed (with supervision) the therapist's role. The mothers were taught to use positive environmental events (consequences) whenever the children responded to expectations for behavior. Straughn (1964) used a similar procedure to instruct mothers in systematic application of behavior principles with children. It was concluded that the therapist should concentrate on instructing mothers to increase appropriate child behavior, rather than just on techniques to decrease inappropriate child reactions.

Hawkins, Peterson, Schweid, and Bijou (1966) removed the behavior intervention instructional environment from the clinic to the more natural setting of the home. Through observing the child-mother interaction, it was determined that environmental events applied by the mothers were actually functioning to increase and maintain maladaptive child behaviors. The mother 
was able to alter this interaction pattern by providing attention or consequences to appropriate rather thas inappropriate child behavior. Reduction of maladaptive child behavior was noted by analysis of direct observation recordings of the specific child behaviors. The studies cited used parents as behavior change agents. Behavior principles were taught and demonstrated to a single parent or set of parents.

\section{APPLICATION OF BEHAVIOR PRINCIPLES IN HOME ENVURONMENTS}

From investigations described in the literature two questions may be formulated. They are as follows:

1. Can parent groups attending parent-teacher conferences be taught behavior principles, and can they subsequently apply the principles successfully in the home environment?

2. Can parents of children with academic and nonacademic behavior problems apply behavior principles in the home situation in a manner that will affect growth in academic and nonacademic competencies in the classroom setting?

In order to answer these questions, an investigation was conducted at the Children's Rehabilitation Unit, University of Kansas Medical Center. At the Unit, informing parents of child progress in school was done with a variety of written reports and monthly teacherparent conferences during the academic year. After the first four weeks of the 1968-1969 academic year had elapsed, group parent conferences concentrated upon instructing parents in the systematic application of behavior principles with children. The investigation was designed to ascertain if parents could increase children's academic and nonacademic behavior performances in the classroom by applying behavior change principles in the home situation.

Subjects were five junior high age pupils who had been diagnosed through psychiatric interviews as "emotionally disturbed," and their parents. The pupils were attending school at a special class located at the Unit, and the parents were required to participate as a part of the total intervention program provided for children. Three of the pupils were males and two were females. The educational program was based on the Structured Approach and effective application of behavior principles ensconced within that approach (Haring and Phillips, 1962; Whelan, 1966).

As a portion of the planned classroom program, daily report cards were given to the pupils, who in turn were to show them to the parents. If a pupil did not display the report card, his parents called the teacher to obtain a record of the daily performance in academic-oriented tasks and nonacademic behavior expectations. The report card consisted of numerical scores for items such as number of pages read correctly during the reading class, number of correct arithmetic problems completed, completion of activities required in gym class, points ranging from one (poor) to ten (very good) given each day by the teacher to pupils as an evaluation of interpersonal relationship adequacy, pupil attention to personal care or hygiene on a scale of one to ten, and daily percentage scores for accuracy in history and literature comprehension activities. Each pupil received a daily numerical score in each of the eight categories listed.

During the first four school weeks of the 1968-1969 academic year, each pupil's daily scores in the nonacademic and academic categories were recorded by the teacher. The pupils were not aware that the teacher was keeping these daily records.

After the first month of school, parents were requested to attend a group parent-teacher conference. All of the parents of the five pupils participated in the conferences for the duration of the investigation. Two of the more serious deficiencies pertaining to parent-teacher conferences is that they are scheduled infrequently and are often focused upon child behavior that is excessively deviant. Conferences which dwell only upon unacceptable child behavior in school emphasize the negative aspects. In many instances, such conferences culminate in parental punishment of the child, or formation of a conflict area between teacher and parent which further inhibits the child's ability to function in the classroom.

At the first group conference parents were instructed in behavior recording and graphing procedures. They received an explanation of behavior principles, and methods of applying them to foster or elicit behavior change. The parents were given a copy of the report card that each pupil was expected to bring home on a daily basis. The various categories and the points or scores for each category were described so that the parents could understand the basic concepts involved in the daily evaluation systcm. The parents received instruction in preparing graphs (bar and line) which were displayed in a prominent place in the home. Daily scores in each category were recorded on the graph. In addition to compiling daily graphs, the parents were requested to select at least two or more categories on the report card to discuss with their child each day. The content of the discussion was to be positive and supportive of the child's effort. Comments such as "You did very well in history, and I'll bet that you can also in- 
crease that score in math" were emphasized. Categories selected by the parents remained constant for the length of the investigation. The parents were asked not to disclose the categories emphasized at home to the classroom teacher. The purpose of this procedure was to determine if parents could affect daily classroom performance through application of behavior principles in the home environment. No changes were implemented in the classroom program during the period when the parents were providing positive environmental events (consequences) for performance in the classroom.

Two additional group parent conferences were scheduled in order to answer questions regarding application of behavior principles. After the third conference, and an elapsed time period of four school weeks, the parents informed the teacher of the categories they were concentrating upon in daily discussions with the children. Two of the five parents selected only academic categories to emphasize, and three selected a combination of academic and nonacademic categories.

In order to determine if positive parental attention was effective in changing pupil classroom performance, an analysis of the daily report card data was completed. Mean scores in each of the report card categories were computed for the month prior to parental intervention, and for the month during parental intervention. Gain and loss scores were used in the data analysis. Table I displays the results of the analysis.

TABLE 1

ANALYSIS OF DIFFERENCE SCORES

BETWEEN DAILY REPORT CARD CATEGORIES SELECTED BY PARENTS FOR EMPHASIS IN COMPARISON TO CATEGORIES NOT SELECTED Pupils Daily Report Card Categories

\begin{tabular}{cccc}
\hline & $\begin{array}{c}\text { Before Parental } \\
\text { Intervention }\end{array}$ & $\begin{array}{c}\text { During Parental } \\
\text { Intervention }\end{array}$ \\
\cline { 2 - 3 } & $\begin{array}{c}\text { Combined Mean } \\
\text { Scores }\end{array}$ & $\begin{array}{c}\text { Combined Mean } \\
\text { Scores }\end{array}$ & $\begin{array}{c}\text { Differ- } \\
\text { ence } \\
\text { Scores }\end{array}$ \\
\hline \multicolumn{4}{c}{ Selected Categories } \\
1. & 60 & 77 & 17 \\
2. & 76 & 118 & 42 \\
3. & 89 & 96 & 7 \\
4. & 62 & 63 & 1 \\
5. & 228 & 341 & 113 \\
\hline & 52 & 44 & \\
1. & 52 & 49 & -8 \\
2. & 45 & 40 & -3 \\
3. & 41 & 41 & -5 \\
4. & 63 & 59 & 0 \\
5. & & & -4 \\
\hline
\end{tabular}

Pupils are identified by number. Pupil 2, for example, is the same subject in both the selected and not selected portions of the Table. In analyzing the daily performance data, the report card categories were divided into two section representing categories selected by the parents, and those that were not. A total mean score for each pupil and for each section was calculated. Pupil 2 had a mean score of 76 in the selected categories "Before Parental Intervention," and a mean score of 118 "During Parental Intervention." The effects of parental intervention are demonstrated by a gain score of 42. Pupil 2 lost three (3) points in the not selected categories when the before and during phases of the investigation were compared. These data were analyzed by the Walsh test (Siegel, 1956). It was predicted that parental intervention would facilitate performance gain, so a one-tailed test was used to assess difference

\section{FIGURE I}

Visual display of percent gain and loss differences between daily report card categories selected by parents for emphasis in comparison to categories not selected for the before and during phases of the investigation. [1] and (1) indicates pupil one (I).

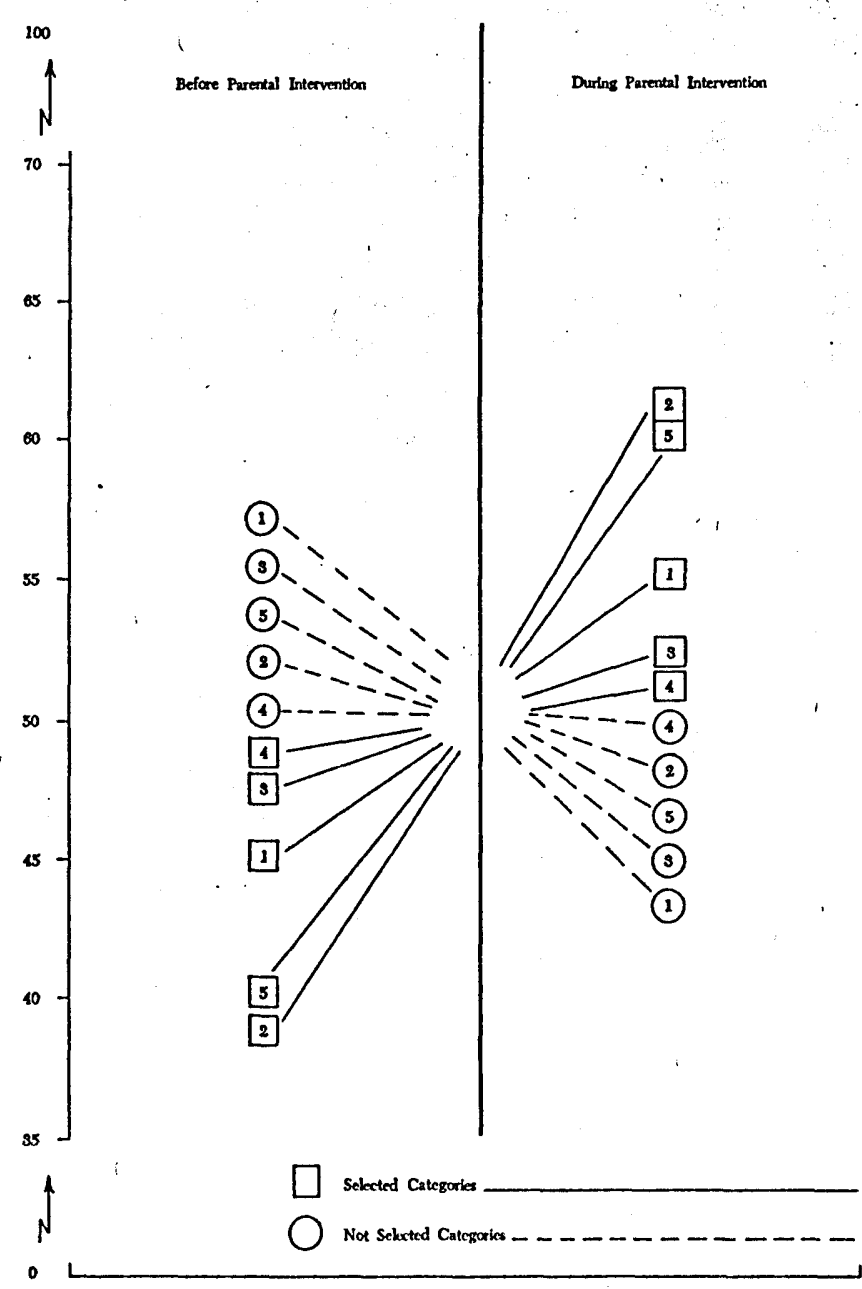


scores for the selected categories. The growth indicated in the difference scores was significant at the .031 level for the selected categories. Since it was predicted that difference scores in the not selected categories would not change, a two-tailed test was used for analysis. Even though all but one of the pupils displayed a negative point loss, these differences between the before and during phases were not statistically significant $(p=.125)$. It is important to note, however, that four of the five pupils did exhibit a decrease in the not selected categories. Apparently the pupils in the classroom were functioning near adequate performance levels, in that increases in selected categories were accomplished with a minimal performance cost or decrease in the not selected ones.

The results of the investigation are shown in Figure 1. It illustrates the percent gain and loss in scores assigned to daily report card categories for the before and during phases of the study. In Table 1 , pupil one (1) achieved a mean score of 60 in the before phase, and a mean score of 77 in the during phase for the selected categories. The combined numerical total for the two phases was 137. 'To calculate the percent gain or loss indicated in Figure 1, it was determined that the numerical score of 60 represented $45 \%$ of the total score (137) and that 77 represented 55\%. While it appears in the figure that selected categories were low prior to initiation of the investigation, and therefore had a higher probability of exhibiting gain or increases, this was not the case. Placement of selected category scores on the lower portion of the figure representing the before - phase is a function of the true numerical score differences when calculated as a percent of total score for each phase of the investigation. Pupil one (1), in the selected categories, achieved a $10 \%$ gain in numerical scores when the numerical scores in the "before" and "during" phases were calculated as a percent of the total numerical score for both phases.

This investigation, even though simple in design and execution, demonstrated that parents can become active participants with teachers in assisting children to change behavior along productive and positive dimensions. It provides evidence that can be used for an affirmative answer to the two questions which formed the basis of the investigation. Teachers, by instituting parent conferences of the type described, can enlist parental involvement to support the classroom program.

In subsequent conferences, the parents reported that they were relating to their children in a more positive fashion, and generally believed that the child-parent relationship had substantially improved.

\section{APPLICATION OF BEHAVIOR PRINCIPLES} IN CLASSROOM ENVIRONMENTS

Classroom-oriented application of behavior principles has been reported and demonstrated to be effective (Lovitt, 1969; Whelan, 1966). At the Children's Rehabilitation Unit, staff members are continuing to refine the concepts associated with the Structured Approach and behavior principles as they relate to the development of more effective teaching procedures, and improved classroom organization.

Three teachers of children diagnosed as "emotionally disturbed" planned a program that enabled older children to serve as tutors for younger children in the classrooms. Older children contracted with the teacher to tutor other children only when a specified number of assigned tasks were adequately completed. Younger children were informed by their teacher that if a specified number of tasks were completed, an older child would be available to assist them in other task assignments. The number of tutoring sessions increased over elapsed school days, and the children completed assigned tasks in order to participate in the cooperative tutorial sessions. The teachers also noted that tutorial sessions did not dissolve in patterns of conflictual interaction between the children. Comments such as "Thank you for helping me" were observed at the termination of each tutoring session, and both the older and younger children seemed to benefit from the interaction. This impressionistic view of the positive effects emanating from a system of child-child instructional sessions needs to be subjected to more scientific investigation and subsequently reported in the literature. Such efforts are currently in process at the Unit. However, as is true in other situations where behavior principles are applied, the use of peers to assist peers needs to be carefully planned if the results are to be positive in terms of helping children learn self-control and successful coping behaviors.

Teachers, when describing a behavior of an individual child, often express concern regarding school tasks that are not completed because the child wastes time and seemingly does not have the self-control or motivation to begin and complete a realistic assignment. The data displayed in Figure 2 represents an example of teacher application of behavior principles to assist a child who was not completing arithmetic problems in an acceptable fashion. The teacher noted that the child was quite accurate in problems that were completed, but that he spent most of the arithmetic class period looking around the room, playing with a pencil, drawing, etc.

The teacher believed that the task expectations were 
realistic and within the child's ability level. A decision was made to plan an academic behavior intervention program that would operate to increase completion of arithmetic problems during the class period. According to the teacher, accuracy of completed work was not the major concern; therefore the intervention program was organized to enable the child to complete as many arithmetic problems as possible within a 30 -minute class period.

An intervention program and the effects of that program are portrayed in Figure 2. The program was divided into "before," "during," and "after" intervention

\section{FIGURE 2}

Effects of a child-teacher contract for completion of arithmetic skill problems. Contract specified that child could earn time to play with a puppet if problems were completed within thirty minutes.

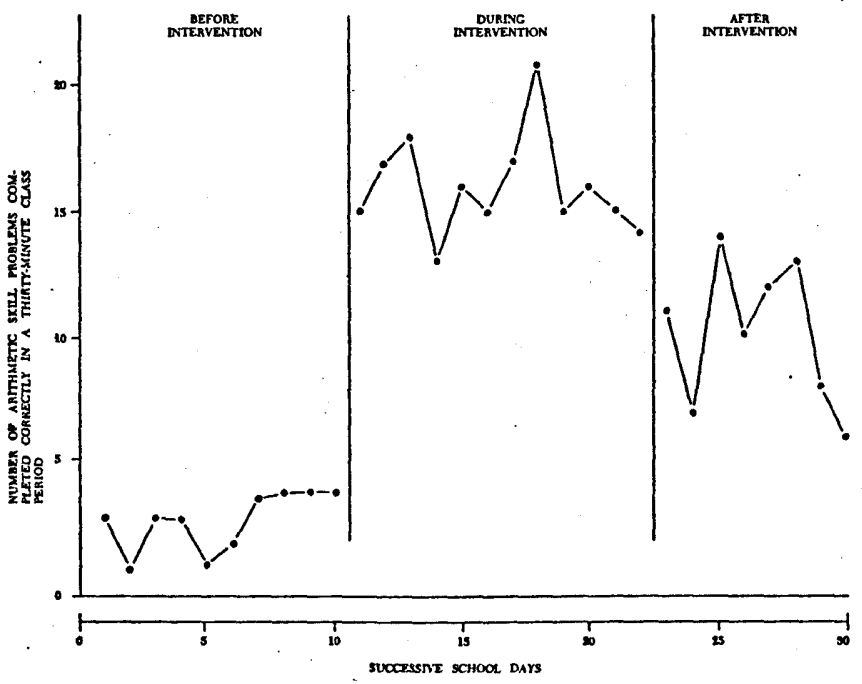

phases. Upon noting that the child did not complete most of the assigned task, the teacher recorded arithmetic problems completed correctly for 10 successive school days (Before Intervention). Each arithmetic assignment involved 19 to 22 skill-building problems that were to be completed within a 30 -minute daily class period. As indicated, the child never completed more than four problems during a class period for the duration of the "Before Intervention" phase.

In attempting to ascertain and select an environmental event (consequence) that could be used for motivation purposes, the teacher observed that the child often played with a puppet (available in the classroom for children to use) whenever time was allowed for individual selection of activities. The teacher believed that an opportunity to play with the puppet contingent upon completion of assigned arithmetic tasks could be an effective intervention variable to apply. On the eleven- th day of the behavior intervention program the teacher initiated the "During Intervention" phase. Essentially, the teacher and child formulated a contract which stipulated that if the child completed the assigned arithmetic task within thirty minutes, time to play with the puppet would become mediately available. To determine if the intervention variable (puppet play) was effective as an environmental event that occurred after the specified arithmetic task completion behavior (consequence), the teacher continued to record daily problems completed correctly. As can be discerned in Figure 2 the child was able to complete a significant number of the assigned tasks. The During phase was in effect for 12 days.

Comparison of the daily arithmetic scores between the Before and During phases seemed to indicate that the opportunity to earn time to play with a puppet was an effective intervention variable or environmental event (consequence). However, the teacher was not entirely convinced that the puppet was the variable affecting the increase in problems completed correctly. Perhaps the increase could be attributed to simpler task assignment or other environmental events operating that were not recognized or planned by the teacher. Therefore the During phase was terminated, and the After phase began on day 23 of the behavior intervention program. Eight days of arithmetic problems completed correctly were recorded and are labeled in Figure 2 as the "After Intervention" pliase. For this case, the After phase is a return to the same classroom conditions that existed in the Before phase. The number of problems completed correctly decreased when compared to the During phase, but did not return to the same level recorded for the Before phase. However, data recorded in the After phase provided additional verification that the intervention variable (puppet play) was effective in increasing the number of arithmetic problems completed correctly.

The fact that arithmetic problems completed correctly decreased daring the After phase provided evidence to the teacher that the intervention variable (puppet play) was removed too soon, and that an additional intervention vamiable would have to be selected if arithmetic problems completed accurately were to be maintained at an acceptable daily level. Data observed and graphed in the ffter phase did not reach the level graphed in the Before phase. This provides some support for the speculation that the child was realizing some satisfaction from interacting with the task. That is, selfmotivation that is developed through interaction with a task, and the soccessful completion of that task, seemed to be functioning with some effect. Developing selfmotivation, self-control, and the desire to complete a 
task is the goal of most classroom academic behavior intervention programs. Therefore, intervention variables (such as puppet play) are not applied unless necessary, and if applied, are removed as soon as possible. Continued recording of the specified behavior to be changed cnables a teacher to determine in a systematic fashion the point in the total behavior intervention program when the intervention variable can be removed without substantially affecting or decreasing the child's behavior performance.

As was stressed in the parent conference (behavior intervention program doscription), the child-teacher program was designed to concentrate upon increasing the occurrence of positive, productive child behavior. The teacher could have chosen to deprive the child of a minute of recess for each arithmetic problem not completed, but this represents a negative and inappropriate application of behavior principles. With this type of plan the child would probably have performed just to avoid painful environmental events. Under such conditions it is doubtful that the self-motivation established from positive application of environmental events for efforts reflecting growth in adaptive behavior could be developed adequately. Whenever possible, a teacher should select a positive approach in planning behavior intervention programs with and for such a child. However, there will be instances, when the teacher will have to initiate procedures to decrease child behaviors, such as hitting other children. In these cases realistic penalties or environmental events, e.g. withholding of a privilege, may have to be applied. Careful attention to the systematic, correct, and effective application of behavior principles to change children's behavior should be a paramount consideration for teachers and parents.

\section{REFLECTIONS UPON APPLICATION OF BEHAVIOR PRINCIPLES}

It is necessary and important to recognize that behavior change procedures, and the behavior principles upon which they are based, are essentially neutral. That is, the procedures are not inherently good or bad. Individuals select the procedures, then apply them in a negative or a positive manner.

If behavior change procedures continue to be demonstrated as effective methodology to alter behavior, then it is important to prepare teachers and parents in the judicious use of these procedures. It has been demonstrated that behavior principles can be applied in home and classroom environments, and that such applications produce behavior changes. The instances reflecting incorrect or negative application do not mean that the principles are incorrect; they substantiate the fact that individuals are capable of making errors, and that some individuals will use any opportunity to control or punish children.

The process of maturation implies that behavior can, must, and will change. A major responsibility assigned to parents and teachers is to plan for positive changes in children's behavior. When children's positive growth processes are disrupted or become fixated it is required that teachers and parents implement behavior intervention programs that will enable children to continue the development of behaviors that are creative, independent, self-motivated, and productive. These are goals to which all philosophically divergent behavior intervention approaches aspire in planning programs for children who need external assistance and guidance.

If it can be demonstrated that teachers and parents can be taught to utilize behavior principles to change behavior in a sensitive, organized, systematic fashion, then it is necessary to prepare individuals in the correct application of such principles. Environmental events (stimuli and consequences) function continuously whether or not teachers and parents are aware of them, or even if they decide not to utilize such events to foster behavior change. If children can be assisted by the correct manipulation of environmental events, it is vital that individuals who interact with children be instructed in appropriate application procedures. To do less is tantamount to irresponsibility, and even more important, results in the neglect of those children who are in need of and deserve the most effective behavior intervention programs available.

\section{REFERENCES}

Ayllon, T. and Michael J. "The Psychiatric Nurse as a Behavioral Engineer." Journal of the Experimental Analysis of Behavior, $1959,2,323-334$.

Bijou, S. W. and Baer, D. M. Child Development Vol. 1. New York: Appleton-Century-Crofts, Inc., 1961.

Bijou, S. W. and Baer, D. M. (Eds.) Child Development: readings in experimental analysis. New York: Appleton-Century-Crofts, 1967.

Boyer, W. H. and Walsh, P. "Are Children Bom Unequal?" Saturday Review, 1968, 61-79.

Eysenck, H. J. "The Effects of Psychotherapy." In H. J. Eysenck (Ed.), Handbook of Abnormal Psychology. New York: Basic Books, 1961. Pp. 556-610. (a)

Eysenck, J. H. (Ed.) Handbook of Abnormal Psychology. New York: Basic Books, 1961. (b)

Gallagher, P. A. "The Influence of Two Learning Conditions on Emotionally Disturbed Children's Acquisition of Academic Behaviors." Unpublished doctoral dissertation, University of Kansas, 1968.

Haring, N. G. and Phillips, E. L. Educating emotionally disturbed children. New York: McGraw-Hill, 1962. 
Hawkins, R. P., Peterson, R. F., Schweid, E., and Bijou, S. W. "Behavior Therapy in the Home: Amelioration of Problem Parent-Child Relations With the Parent in a Therapeutic Role." Journal of Experimental Child Psychology, 1966, 4, 99-107.

Hewett, F. M. The Emotionally Disturbed Child in the Classroom. Boston, Mass.: Allyn and Bacon, Inc., 1968.

Hilgard, E. R. Theories of Learning. New York: AppletonCentury-Crofts, Inc., 1956.

Holland, J. G. and Skinner, B. F. The Analysis of Behavior. New York: McGraw-Hill, 1961.

Jessell, J. C. and Rothney, J. W. The Effectiveness of ParentTeacher Conferences. Personnel and Guidance Journal, 1965, 142-146.

Krasner, L. and Ullman, L. P. (Eds.) Research in Behavior Modification. New York: Holt, Rinehart, and Winston, 1966.

Kroth, R. L. "A Study of Three Aspects of Time Among Normal and Delinquent School Age Males in Costa Rica and the United States." Unpublished doctoral dissertation, University of Kansas, 1968.

Krumboltz, J. D. (Ed.) Revolution in Counseling. New York: Houghton Mifflin Co., 1966.

Lovitt, T. C. and Curtiss, K. A. "Academic Response Rate as a Function of Teacher and Self-imposed Contingencies." Journal of Applied Behavior Analysis, 1969, 2, 49-53.

Lucero, R. J., Vail, D. J., and Scherber, J. "Regulating Operant Conditioning Programs." Hospital and Community Psychiatry, 1968, 41-42.

McGowan, R. J. "Group Counseling With Underachievers and Their Parents." The School Counselor, 1968, 30-40.

Merrill, B. A. A Measurement of Mother-child Interaction." Journal of Abnormal Social Psychology, 1946, 41, 37-49.

Michael, J. and Meyerson, L. A. "A Behavioral Approach To Counseling and Guidance." Harvard Educational Review, 1962, 32, 382-402.

Rosenthal, R. and Jacobson, L. Pymalion in the Classroom. New York: Holt, Rinehart, and Winston, 1968.

Russo, S. "Adaptions in Behavioral Therapy With Children." Behavior Research and Therapy, 1964, 2, 43-47.

Siegel, S. Nonparametric Statistics for the Behavioral Sciences. New York: McGraw-Hill, 1956.

Skinner, B. F. Science and Human Behavior. New York: Macmillan, 1953.

Skinner, B. F. “Operant Behavior." American. Psychologist, $1963,18,503-515$.

Straughn, J. "H. "Treatment With Child and Mother in the Playroom." Behavior Research and Therapy, 1964, 2, 37-41.

Thomas, E. J. (Ed.) The Socio-behavioral Approach and Applications to Social Work. New York: Council on Social Work Education, 1967.

Ullmann, L. P. and Krasner, L. (Eds.) Case Studies in Behavior Modification. New York: Holt, Rinehart, and Winston, 1965.

Voelker, P. H. "Administration and Supervision of Special Education Programs." In W. M. Cruickshank and G. O. Johnson (Eds.), Education of Exceptional Children and Youth. Englewood Cliffs, N. J.: Prentice-Hall, Inc., 1967. Pp. 670-809.

Volsky, T., Magoon, T. M., Norman, W. T., and Hoyt, D. P. The Outcomes of Counscling and Psychotherapy. Minneapolis,

Minn.: University of Minnesota Press, 1965

Wahler, R. G., Winkel, G. H., Peterson, R. F., and Morrison, D. C. "Mothers as Behavior Therapists for Their Own Children." Behavior Research and Therapy, 1965, 3, 113-134.

Whelan, R. J. and Haring, N. G. "Modification and Maintenance of Beliavior Through Systematic Application of Consequences." Exceptional Children, 1966, 32, 281-289.

Whelan, R. J. "The Relevance of Behavior Modification Procedures for Teachers of Emotionally Disturbed Children." In P. Knoblock (Ed.), Intervention Approaches in Educating
Emotionally Disturbed Children. Syracuse, N. Y.: Syracuse University Press, 1966 . Pp. 35-78.

Whelan, R. J. and Gallagher, P. A. "Effective Teaching of Children With Behavior Disorders." In N. G. Haring and A. H. Hayden (Eds.), Instructional Improvements Behavior Modification. Fort Steilacoom, Washington: Child Study and Treatment Center, 1968. Pp. 164-198.

Wolpe, J. and Lazarus, A. A. Behavior Therapy. Techniques. New York: Pergamon Press, 1966.

Wood, F. H. Behavior Modification Techniques in Context. Newsletter of the Council for Children with Behavior Disorders, $1968,5,12-15$.

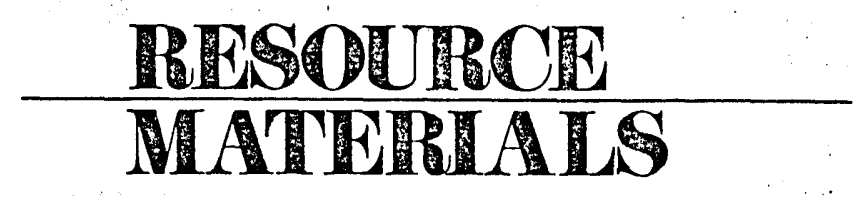

By Reuben Altman and Linda Smith ${ }^{1}$

\section{ARDELLE MANNING PRODUCTIONS}

Ardelle Manning produces materials in the content areas of history, music, and home economics, providing worktexts, curriculum guides, and recordings. While these materials were designed primarily for the mentally retarded, the publisher reports successful use with the emotionally disturbed and the blind.

A Modified History of the United States covers such topics as early exploration, the Civil and World wars, and the United Nations, while directing special attention to language development through pertinent vocabulary lists and exercises. An accompanying workbook is intended for independent student work, obviating the need for teacher supervision. A curriculum guide for the trainable mentally retarded emphasizing the sequential progression of abilities underlying food preparation skills is also available. Materials range in price from $\$ 1.00$ to $\$ 5.95$. For information about these or other materials, write: Ardelle Manning Productions; Post Office Box 125; Palo Alto, California 94302.

\section{A. DAIGGER AND COMPANY}

Guided by Montessori methods for early childhood education, the Educational Teaching Aids (ETA) Division of A. Daigger and Company manufactures manipulative materials utilized in both preschool and special education classes. Individual items concentrate on the mastery of particular self-help skills including buttoning, lacing, snapping, and zipping. This aproach accentuating manipulation is evidenced throughout ETA's line of instructional materials. For the develop-

${ }^{1}$ Reuben Altman is Consultant and Linda Smith is Curriculum Specialist, Special Education Instructional Materials Center, University of Texas at Austin. 
ment and refinement of perceptual abilities, ETA provides aids in tactual discrimination, eyc-hand coordination, size, form and color discrimination, and spatial concepts. The Unifix Mathematics Kit employs colorful interlocking cubes to promote competence in numeral notation, place value, set theory, and other basic mathematics concepts. For a free annotated catalog noting prices, write: A. Daigger and Company; Educational Teaching Aids Division; 159 West Kinzie Street; Chicago, Illinois 60610 .

\section{ISSULS

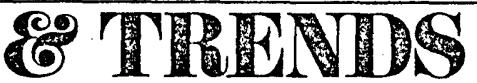

The relative merits of labeling versus the often negative consequences of labeling are currently the subject of considerable discussion. Following is a statement prepared by the special education staff who teach children with social and cmotional problems of the Marshallton-McKean School District of Wilmington, Deleware. The recommendations call for elimination of the special class concept and cmployment of a resource-type model. The statement is reported in its entirety as presented to their local advisory committee.

\section{LEARNING CENTERS: AN ALTERNATIVE TO SPECIAL CLASSES}

By Robert P. Ferrara, Kanthi S. Iyengar, and Donald J. Hayman ${ }^{1}$

The entirc staff that is presently serving the needs of twenty-eight children who are experiencing emotional and social difficulties recommend strongly and urgently the complete elimination of the special classes that are now in operation. The elimination should begin now.

Dr. M. J. Trippe of the University of Michigan refers to special classes as "monstrous containment facilities that are little more than holding operations for troublesome children." Dr. L. M. Dunn, past president of the Council for Exceptional Children, said in September, 1968; "Regular teachers and administrators have sincerely felt they were doing these pupils a favor by removing them from the pressures of an unrealistic and inappropriate program of studies. Special educators have also fully believed that the children involved would make greater progress in special schools and classes. However, the overwhelming evidence is that our present and past practices have their major justification in removing pressures on regular teachers and pupils, at the ex-

1. Robert P. Ferrara, Kanthi S. Iyengar, and Donald J. Hayman are teachers of children with social and emotional problems in the Marshallton-McKean School District of Wilmington, Delaware. pense of the socioculturally deprived slow learning pupils themselves." Dr. Dunn also said, "This expensive proliferation of self-contained special schools and classes raises serious educational and civil rights issues which must be squarely faced." The September-October issue of the Intermediary (the official publication of the Special Education Instructional Materials Center of the MidAtlantic Region) stated that the child's IQ score "may be damnable misleading, as in the hands of those who label any child scoring below a certain figure as noneducable or educable only to a certain point, and leave him in an environment where the description is likely to become true." That "environment" referred to is the special class. The special class is certainly not conducive to a learning situation-putting all the hyperactivity together in one room is only conducive to extreme hyperactivity. The services of the special teacher are not fully utilized when his services are limited only to a special class. The stigma that accompanies placement in a special class is devastating to the self-estem of any child. More than two years ago, the first special class in the Marshallton-McKean School District for children with emotional and social problems was started. There were ten boys assigned to that class and today nine of those ten boys are still in a special class. One boy is now being called mentally retarded.

The following is a very brief description of a plan that is conducive to learning, that does fully utilize the services of the special teacher, and most important of all, is not harmful to children and can be successful. All children experiencing learning difficulties, whether that difficulty is primarily a result of emotional problems, learning disabilities, or mild mental retardation, should be assigned to a regular homeroom-there are no special classes. Located in several learning centers will be supportive services and materials for those children. Some children will require more help than others, depending on the individual child and his needs. It is of paramount importance that the child always reports to his homeroom in the morning, eats with his regular classmates, and leaves with his homeroom group at the end of each school day. The child participates in his regularly scheduled daily activities whenever this is advantageous for him. His school records and progress reports should be maintained and kept by the special teacher who is working with the child in the learning center. The special teacher, unlike a so-called "crisisteacher," should be properly qualified in the field of special education. Through this plan the child can identify favorably with the mainstream of the school while receiving the help of the supportive services offered by 
the learning center.

Normalization in special education cannot take place through the continuance of special classes. It is our sincere hope that our advisory committee will help the special education staff to be truly innovative. Special classes are not innovative, and they are harmful and unfair to those children who are placed in them.

A constructive and innovative plan has been suggested , and we believe it is worthy of careful consideration. This plan is not being suggested so it can be thought about for next year or some time in the future; it should be given serious consideration for immediate application. This plan can work, if you want it to work. We are presently servicing twenty-eight children when our services should be available for the entire school population.

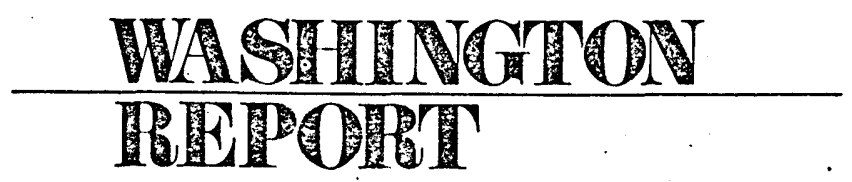

In review of a possible cut in already reduced funds for 1970 Health, Education, and Welfare programs for the handicapped, groups of special educators have appealed to President Nixon and HEW Secretary Robert Finch to reconsider the funding.

The Council for Exceptional Children, a professional organization of 38,000 special educators, sent a telegram to the President and Secretary Finch urging them to readjust the special education budget as it was "inequitable in terms of other education expenditures." John Melcher, President of the Council for Exceptional Children, sees the reduction not only as a hardship for special education programs but as a threat to the goal of making education available to every handicapped child.

In late February the Department of Health, Education, and Welfare submitted the figure of $\$ 92$ million as a compromise to the original special education budget the President had vetoed in January. A more recent proposal calls for an additional cut of $\$ 7$ million. If the cut is approved its effect would be felt primarily in early childhood education, research, and personnel training.

Also affected will be the budget for rubella vaccine. A substantial cut is proposed at a time when a highly preventable rubella epidemic threatens the nation. The last such epidemic severely handicapped 30,000 children. Such a measure seems less than economically sound in view of the expense of providing special programs for the children who could be handicapped because of reduced availability of vaccine.

\section{NEW COLUMN}

This message is addressed to our readers who possess creative spark and the wisdom that comes from experience.

The editorial board of FOCUS ON EXCEPTIONAL CHILDREN has decided to initiate a new column to explore possible solutions to classroom problems. The intent is to provide a format for discussing problems in behavior, instruction, peer relations and other matters of concern to classroom teachers. Dr. Austin J. Connolly of the University of Missouri will edit this new column.

Each issue of FOCUS ON EXCEPTIONAL CHIL$D R E N$ will pose a pertinent problem which will hopefully elicit suggestions from teachers regarding their possible solution or alleviation. All readers are invited to send in solutions. A subsequent issue will summarize the contributions by readers and may include condensations of specific suggestions. A new problem will be posed each month.

FOCUS ON EXCEPTIONAL CHILDREN will award complimentary subscriptions for the best idea each month.

\section{PROBLEM 1}

You have a boy in your intermediate class for the educable mentally retarded who seems to read silently with comprehension. When reading orally, he makes omissions, has many reversals, and demonstrates other perceptual motor disturbances. He is twelve. Should you have him read silently and ignore his perceptual motor problems or should you attempt to cope with them? If so, how?

\section{PROBLEM 2}

There is an emotionally disturbed girl in your elementary classroom who is having learning problems. She is nine. You feel the problem is the mother and too much pressure on the child for good performance from home. All attempts to get the mother in for a conference have failed. There is some evidence that the child is attempting to manipulate the mother. Can this child be helped? How?

All readers are invited to send their solutions and tell how they would handle these situations. The September, 1970 issue will summarize problem one and the October, 1970 issue will summarize problem two. Send your solutions to the Editorial Offices, FOCUS ON EXCEPTIONAL CHILDREN, 6635 East Villanova Place, Denver, Colorado 80222. 